\title{
Social Work (Social Policy) Used as a Tool of Social Control
}

\author{
Zeinab Abulhul1,2 \\ ${ }^{1}$ Department of Center for Social Work Education, School of Health and Human Services, Widener 2 University, Chester, PA, USA \\ ${ }^{2}$ Department of Social Work, University of Tripoli, Tripoli, Libya \\ Email: abulhul@gmail.com
}

How to cite this paper: Abulhul, Z. (2021). Social Work (Social Policy) Used as a Tool of Social Control. Open Journal of Social Sciences, 9, 249-262.

https://doi.org/10.4236/jss.2021.91018

Received: December 17, 2020

Accepted: January 22, 2021

Published: January 25, 2021

Copyright (C) 2021 by author(s) and Scientific Research Publishing Inc. This work is licensed under the Creative Commons Attribution International License (CC BY 4.0).

http://creativecommons.org/licenses/by/4.0/ (c) (i) Open Access

\begin{abstract}
This article aims to define and describe social work (social policy) as a social control tool. This article analyzes and studies social work's implications as a social control tool on social, cultural, economic, and political aspects. This article also illustrates social control's implication on the political, social welfare, Social work, and social work implications as a social control tool in social work future research. The author uses the method of critical thinking by shed lighting the sociologists' definitions of social control, the purposes of social control, and its forms in the community. The author aims to raise awareness among social workers about the importance of their role to defend the profession of social work to meet people's needs and maintain social stability. They may do so by playing a mediate role between achieving government policy plans and meeting people's needs by using the government needs to social workers' services as an opportunity to apply the social work profession and empower people in need to easy access to the community resources and meet their needs and maintains social stability and economic prosperity.
\end{abstract}

\section{Keywords}

Welfare, Cultural, Policy, Research, Critical, Government Need, Empower, People, Community, Resources Stability, Prosperity

\section{Introduction}

Social control is social operations that have methods to regulate relationships among individuals and groups through social institutions to ensure promoting the welfare of the society as a whole (ICHRP, 2010). According to Mannheim's definition, as cited in Fundamentals of Sociology (Bhushan \& Sachdeva, 2012). "Social control is the sum of those methods by which a society tries to influence 
human's behavior to maintain a given order" (p. 158). Social control could influence individuals by involving general views, social propositions, and places of worships. Additionally, the social control's influence might be by a group who has power over an individual; this group could be a family, school, religion, union or state (Bhushan \& Sachdeva, 2012).

\section{Social Control}

Social control as defined by sociologists has two basic forms, internal and external forms of norms and values that regulate people's lives. An internal form of informal social control is the influence of informal social networks like family, peer group, neighborhood, and religion. Those forms have control over individuals and regulate social lives. Thus, individuals exert their effort to meet social expectancy because of the fear of social rejection or isolation. However, the influence of informal social control in the wide scope, such as big cities does not work well. In modern cities, individuals ignore social norms which leads to social disorder. Thus, internal social control is insufficient to control the social order, so it needs support from the external norms to maintain social order. The external formal social norms imply some sanctions, whether rewards or punishment, such as government laws to govern people's interaction and maintain social stability (Kareev, 2013).

Thus, social work is used by governments as formal social control and by the people as an informal social control. "Social work as a vocation, profession and discipline have evolved during the last 150 years. It has reached different levels of acceptance in countries across the world, been banned by authorities and reappeared. Due to its theoretical impetus as well as to its moral aspects, social work is hard to ban over time" (Zahl, 2003). Historically, formal social control as a concept occupied an important place in the late twentieth century when the sociologists encountered social problems of social order in urban society, which led to interpreting social control in urban areas differently than rural areas. According to Roos and Cooley as cited in Liska (1992), social control in cities has changed because of the lack of social relationships where these relationships are known as mechanisms of social order and ensure the social stability.

Social controls may be implemented through two methods, formal social control, and informal social control. The official way is supported by the value system of the society and is enforced by the local laws of society. Thus, usually, the society's law punishes to keep order and prevent deviance. The second way of social control is an unofficial way. It includes two types of social control: first, those voluntarily used in a social work situation which does not necessarily have specific legal support. Second, those who control their value system during the life process, such as the commitment of individuals toward their religious or ethical values that prevent them from deviance (Evens, 1973). In addition, the power of using social control is dependent on the level of the issued behavior of individuals. Thus, when behavior tends to be deviant, the power of social control is 
at a higher level and becomes strict, while when the behavior meets the expectation of society, the social control becomes a defender of individuals (Chaurand \& Brauer, 2008).

The purpose of social control is regulating people's lives within their social interactions with their social environment. Also, it ensures that people live in a healthy social environment. Additionally, it brings solidarity among people and unites their goals for the sake of their society. However, applying social control is different from one society to another. Historically, the duty of a government is using official regulations and making sure its people have accepted these and have understood what the government expects from them and what is their concern. Therefore, the importance of the role of social work in assisting people appeared. Consequently, social workers work through official channels to defend people's social rights, and also to obtain intended goals; first, to make sure that people in need are receiving adequate services; second, to make sure that they are close to the official circles where the policymakers are cooking up their decisions regarding social services (Cowger \& Atherton, 1974).

\section{The Implications of Social Control on Economic Aspects}

Evaluating the influence of contemporary political, economic, and social factors on social control has become clear to the policymakers because it has affected people's social lives, regarding taking advantage of sharing local people, such as voluntary groups and neighborhoods in social control to achieve stability in community social development. However, the contribution of local people became weak because the government gave up its responsibilities for health care, job opportunity, and racism and minority rights. The neglect led to increasing the rate of people in need. The consequences were increased poverty due to unemployment, low wages, lack of health care, racism, and life pressures, as well as increased discontent among people. In addition, misusing social control by a government for the sake of a limited number of people, which increased, in turn, led to the manifestation of bad social conditions. Bad situations led to higher rates of crime and drove society to instability which burdened the government budget (Henderson \& Vercseg, 2010).

The misuse of social control regarding the tension of minorities between local people in society led to increased violence among social members. This tension came as a result of that the minorities cognition that government should use social control equally among its members by law. Also, government should mitigate the tension among its society members in order to maintain individuals' social interactions in a healthy way to achieve social stability. However, the government uses social control to serve its policy to protect a limited number of people and overlooks people who have social problems. Thus, the state government uses strict control mechanisms to maintain social conditions and keep social stability, such as using high sanctions to control people's behaviors to follow the standard of contemporary society. For example, the U.K experienced tension 
from towns in northern England that faced violence activities from some discontented individuals in a society which caused social disorder because of misusing of social control as people understood that social control should be (Henderson \& Vercseg, 2010).

According to Schissel (1992), there is a nexus between increasing the rate of committing a crime and economic crisis. During an economic crisis, a government becomes unable to provide job opportunities to many people and unable to find a solution for people who have lost their jobs. As a result, the rate of crime increases because of negligence, and a marginalization policy. Thus, government uses the power of social control by using its representatives, such as police and officials who work for the government, to use strict ways to apply the government version of social control to deter deviance and decrease the rate of the crime to ensure social stability without looking for the origin of the deviance problem (Schissel, 1992).

\section{The Implications of Social Control on Social Aspects}

Stability of people's social lives relies on the volume of positive influence that derives from social norms in their social environment. Therefore, social norms work as a guide to social interactions to help people respond appropriately to social situations that fit societal culture. Also, the function of social norms as social control regulates behaviors' forms within individuals' social relationships to protect society from social deviance. The role of social control of deviance in a community can relate to "institutions, policies, government officials, specialists, professionals" (Shipunova, 2016). Also, social control of deviance explains the reason for accepting these norms voluntarily because it refers to "the intersubjective agreement of the intentions and guaranteed by the general recognition of its obligations" (Shipunova, 2016). Thus, social norms translate the meaning of social interactions in social situations to individuals and direct them the way that can be accepted by individuals in social reality in a normal way. For example, currently, many societies changed the influence of social norms for the sake of government interest by using technology, such as using the influence of the internet to manipulate the social norms conceptions by translating the meaning of social norms in the way that serves state policies and material life. That manipulation negatively impacts individuals and makes it difficult for them to distinguish between what is normal and what is deviant (Shipunova, 2016).

Social deviance forms emerge in some individuals' behaviors, such as assault, property destruction, robbery, homicide as expressing their feelings that they are dissatisfied with their social situation. Individuals who are unable to maintain a balance between internal and external social norms and compliance to social control in their relationships are unable to integrate into their society. Therefore, some individuals who are unable to make a social adjustment and at the same time experience social problems, such as divorce, aggression, and assault, usually act violently, and some individuals go further than that, such as committing sui- 
cide as an escape from their poor social situations (Manning, 2012).

The level of social adjustment to social norms among people is different from country to country; people's acceptance of social norms determines the way they deal with them. For example, in China, the social norms and social control are protected by the culture. Thus, people's obligation to their social control is important in order to regulate their relationships and obtain social acceptance. According to Agnew, (as cited in Bao, Haas, Chen \& Pi, 2014) a study using the "bond theory" showed that there is a relationship between strain and crime. Also, Agnew mentioned that the importance of having good social relationships among adolescents and their parents and teachers as well with their traditional institutions, such as family and schools to prevent them from breaking the law and acting violently. In contrast, when individuals encounter repeated strains without social support, the bond of their relationship takes an opposite direction because the strain affects their emotions, and their traditional activities and beliefs. As a result, these individuals reduce their obligation to the traditional institutions and decrease their bond and coherence of their relationships toward the traditional institutions. That leads to weakened individual perspective toward norms of social control and makes them susceptible to committing crime (Bao, Haas, Chen \& Pi, 2014).

\section{The Implications of Social Control on Social Culture}

Culture and belief are elements embedded in social norms, as well as their level of influence on social control, but people's tendencies are different from society to society. Also, social culture is considered an informal social control because it relates to people's privacy, and their obligation towards the traditional relationships is derived from their customs, heritage, and religions. Therefore, individuals deal with their society based on mutual benefits, so they voluntarily follow the rules of social control in order to get the benefit of social support from their society. Thus, they consider seeking social support out of their society an inappropriate to request and should not rely on it. For example, a study conducted about cultural support compared European Americans, Asians, and Asian American regarding seeking support to deal with their emotional stress. The study showed that Asians were unable to reveal their emotions and social stress to take advice from outside their social units. That is because the bond of social norms that had reared them have shaped their orientation. Therefore, they limited their dependence to their close community under their culture influence (Taylor, Welch, Kim, \& Sherman, 2007).

The influence of social class culture has affected social control. The impact of wealth, good education, good jobs, high salary, a high social status shaped high social class positions within society as well its culture and made people consider themselves upper social class, different from other social classes that do not have the same material elements. Therefore, these upper classes tend to isolate themselves from the rest of the society, to live in high-level areas where they can find 
rich people who have the same conceptions of material life. They share the same vision. An Upper-classes culture shaped people's behavior and made their conceptions about other classes. They valued themselves as upper class. Also, they wanted government to serve them differently from the lower-class. Thus, this culture split people within one society in many categories and each category has value with some material elements (Kraus, Piff, \& Keltner, 2011). Moreover, the influence of social class culture weakened an informal social control among people, while it urged the government's social control representative to serve the upper class as they are an affluent class above the rest of the people. As a result of the influence of a rich class's culture, some governments work ferociously for the sake of the upper class. For example, in the 1960s, "urban renewal" emerged which replaced residential areas with commercial, industrial and institutional construction in order to meet social class desires. Thus, this new society pushed low-income people to live in the suburbs where they found cheap housing (Ehrenreich, 1985).

\section{The Implications of Social Control on the Political Aspect}

According to Andrews (2011), good relationships between government and citizens depends on the strengthening of trust among people and government officials. That can be noticed in the way government provides facilities to its people and helps to discuss the political decisions with community members and accepts people's activities to mobilize themselves to influence the government to change its decisions that do not server the general public. Thus, the high level of collaboration between government and citizens is an indication that the government applies social control in its natural context. In this environment, social capital can help to achieve government's desired goals. This achievement can happen when government understands the value of investing social capital in society's growth and allows social capital to share the national wealth in a wise way. Government policy should consider social capital when planning for social policy because both of them seek benefits for the society. As well, they complement each other (external and internal); the external social capital is a community form, and the internal government lies in organizational forms (Andrews, 2011).

Globalization has impacted the economic and political tendency of the United States in several elements, such as economic inequality, low wages, and decreased social feature which led to increasing social marginalization and in turn led to increasing social deviance and social crisis. Negative factors and socioeconomic and racial discrimination barriers increased the depth of divergence within social class levels. In addition, the economic variables played a key role of preventing low-income electors and the minorities from political contribution while it gave an opportunity to those who owned high income to take the lion's share of political participation. These negative factors altered the form of social services provision and affected social work and social policy as a tool of social 
control. As a result, government policy issued a new meaning of social welfare and social services that matched the contemporary economic and political value and overlooked the social values and social issues of ordinary people (Reisch \& Rohde, 2000).

According to Villarreau (2002), many communities have made changes in their policies in response to contemporary challenges and global economic policies. As a result of new political changes, many communities are negatively affected in their social control in different ways, politically, economically, and socially. For example, in the political dimension, the average of competition has increased between electors and their supporters, which led some supporters to commit crimes, such as homicide and corruption, to success their electors. In addition, when the relationships between people and government are negatively affected, people become skeptical about political institutions and the electors' policies because of the weakness of the bond of social norms. In addition, the decline of the level of welfare networks led traditional institutions, such as parents, families, and neighborhoods to lose their enthusiasm to activate social control among community members to help government maintain social stability. That is because community members knew that the government could apply social control to obtain community objectives and secure solidarity relationships among its members. Since community members did not get what they expected from their community's government, they lost interest in maintaining social norms and monitoring social control processes. These factors led to increasing the rate of social violence and crimes and weakened social control (Villarreau, 2002).

\section{The Implications of Social Control on Social Welfare}

Historically the impact of social welfare on social work as a tool of a social control relied on three functions: Firstly, helping people in need to decrease their suffering of the bad socio-economic situation. Secondly, helping government's policy to retain social order and organize labor market. Thirdly, social workers achieve social reform and compel the government to respond to social changes and help people overcome their poor socioeconomic situations (Gambrill, 1997). Also, the contribution of social work as a tool of social control came as result of social workers participation in many reform movements. For example, social workers contributed in civil right movement, women's movement, and trade union. As well as, social workers contributed in recently social welfare movements and workers as defenders for special needs and mantel health movements users social service. Besides, as well social work encouraged as a social control tool to use their professional performance to ensure the achievement people with disabilities rights and obtain the right to have equal relationships with workers and service users. Thus, social work urges social welfare to provide suitable services for people with disabilities that fit their needs and help them to be independent. Moreover, social work as a tool for social control process advocate for people with disabilities to secure their rights under the law to continue their ser- 
vices of social welfare (Ferguson \& Michael, 2007).

Since social control represents the hand of government by Law, it distracted the professional role of social work. The government accepted social work as tool control to its policy to prevent society from social deviance that could lead to social dysfunction. Therefore, the social control uses social work as a tool of the re-equilibrating deviant behavior among individuals and groups. Thus, social work works in the framework of the government policy in both private and public social institutions. Although social workers disagree to be the tool control of a government, however, they aim to practice their work by applying professional procedures that include social diagnosis, and social treatment for their clients. As well as, when social workers work as a tool of government, it gives them an opportunity to be close to people in need also, it helps them to understand their needs in order to advocate for their rights. Therefore, social work exists in social services to maintain providing social services and make sure that people in need are receiving adequate social services. Also, social work function as a tool of social control in public institutions which provide free services to people in need based on the state policy. Also, social workers work in private sectors to provide services of social welfare for all people based on the state social control as regulators social services (Siporin, 1961).

Social elites use social control tools to protect themselves from individuals who have deviant behaviors that might threaten their social lives. Thus, the relationships of the social elite with lower income people are based on the theory of "threatening." Thus, the social elite's opinion is that it is good to provide some minimum social service for poor people, to protect themselves from them. That is because they expect they will threaten their safety when the chance comes. Therefore, social elites increase the level of social control in society's institutions to prevent poor people from perpetrating illegal activities against the social elite by using social control representative tools, such as police to limit poor people's movements and dealing with them differently. According to Blauner (1969), as cited in Chamlin et al. (2007) the social elite in the United States was working against poor black people and restricted them into "urban ghettos as a form of internal colonialism" (Chamlin et al.: p 133). As well, the government stood beside the social elites regarding the segregation policy to protect the social elites from the threaten of poor people. At the same time, the segregation policy helps the government to easily control poor people's activities and their behaviors (Chamlin et al., 2007).

The state government uses social work as the tool for social control to facilitate its policies. Since social workers are professional and have skills to deal with people's needs and help them to find solutions to their social issues, so the government's policy partially acknowledged that the social work profession is an important profession in its society, and it should practice its work in terms of helping people to meet their needs. However, the government does not give its full acknowledgment to social work profession to practice as it is an independent 
profession, but its acknowledgment to social work profession is limited, just to serve government policy and what fits with government perspective regarding facilitating apply the social policy to ensuring social stability (Lyes, 2012).

\section{The Implications of Social Control on Social Work Practice}

Social work practice has implications for social control in legal circles. Based on social workers evaluations to the social situations and people's needs, the officials can take the legal procedures and provide the needed social service to people in need assistance. For example, in "child protection contexts" the evaluations of social workers for children who need suitable care have a significant role in convincing court to take the right decision that serves the sake of children and assigns the appropriate caregivers in order to maintain custody of children (Healy, 2000).

A vocational intervention of Social Work Practice in addiction treatment helps addicted individuals to lessen from alcoholism disease and social stigma. Social Work practice has a positive effect on addicted individuals who encountered many psychological problems to help them to accept social therapy which was lie in raise the education's level of addicted individuals, and train them to change negative behaviors to protect themselves from going back to addiction and replace it with positive behaviors that help them to embrace a new life in better way (Burman, 2010). With increasing the rate of offenders in the criminal justice, social workers urge by legal officials at courts that deal with social workers who recruited themselves to defend addicted individuals to use a formal social control and use the local law to regulate individual's behaviors. Thus, the social control used social work practice as a facilitating tool to apply government rules to protect its people to fight the deviant behaviors. For example, in the United States and the UK use a social control to punish addicted individuals who want to make money by selling illegal drugs, and break laws by imprisonment. while help parents who suffered from addiction by providing to them suitable treatment to help them back to their lives and their children (Ivory Research, 2017).

\section{Implications of Social Work as a Tool of Social Control in Future Research}

According to Pople and Leighninger (2004), social work practice as a profession has two general objectives; the first objective is helping individuals to cope their social issues in order to become effective individuals in their social environment, the second objective, is that connecting social institution that provides social services with individuals in need. Also, social work practice is the process of positively changing in individuals' behavior and their outlook (Rwomire, 2011).

Social Work in many societies is used by the government as a social tool to control social deviancy and facilitate social service for people. As well it used as a social control to change individual's behaviors to accept social changes through 
its social activities, so social work within societies has many forms that give to it ability intervene and provide assistance to many people who need help within different levels. Therefore, social work forms work through "social work versus society," "social work as a distinct entity independent from society" "social work as an instrument of society" and "social work as an intermediary between the individual and society" (Blair, 2007). This gives a chance to social work to take advantage of its importance to apply social control that serves people in need as well as social work as a profession. That is because Social work as a profession is based on obliged to apply social justice amongst people and advocate their civil rights. Therefore, social work's profession closes to people that made social workers understand people needs and help them to mitigate the socioeconomic pressure by helping them to access to social service. The government used Social work as a tool to apply its policy and use the power of its the law to maintain social stability (Austin, 2014).

From this point, social workers should employ social control for the sake of society by using both informal social control and formal social control through providing activities that motivate people and government to work as one body for the sake of social stability. This way makes government and social workers recognize the issues that cause negative effect people lives and motivate neighborhood to an initiative to help their district by co-operating with officials to solve their community' problems. As well as, contribution between officials, social workers, and public people for the sake of their neighborhood can create trust among these social units and decreas racial discrimination and burden society financially. This can also happen by the readiness of government' officials to cooperate with social workers as the median to balance between informal social control and formal social control and see to informal and formal social control as complement to each other (Drakulich \& Crutchfield, 2013).

Social work profession should upgrade social workers' education and its curricula which should include social policy and policies that do not consider people needs in its priority. In contrast, its application might directly harm people with low income and increase their suffering. Also, social work education curricula should include the importance of social justice in Social Work's education and upgrade its training to help social workers as a social control to keep up with new challenges and produce professionals who can work with contemporary issues that secreted by injustice and inequality (Weiss, Gal, \& Cnaan, 2005).

Social workers as a tool of social control should take advantage of technology to employ informal social control and enhance social change in society by using the influence of the internet. That is because internet includes different of modes and variety of social communication that help people to support social norms and understand the factors that effect their social norms and how to respond to social control. Thus, social workers as social control should use the mean as social reforms tool and create a social environment to recognize social peoples and find a suitable solution through discussing groups as well raise awareness of the 
community about can handle their social problems (DiMaggio, Hargittai, Neuman \& Robinson, 2001).

Besides to internet, there is another useful tool can be used as assistance factor to enhance social control such as using Cinema as a tool for social changing and social control has a strong effect on people behaviors. Social workers and social policy should give more attention to this entertainment factor because it has two functions, it can be used for entertaining its audiences at the same time it can be used as a tool for educating people about their human rights by presenting their social issues and the correct methods to address them as well as help them intact ways to defend their rights. Also, Cinema can be used as a too that influence people to take their responsibility for effecting social control by producing materials that serve social stability and encourage governments for positive changes. Cinema currently plays the key role in influencing its audience to absorb the social values by applying materials conceive importance of social norms in communities. It describes its movie stars as heroes, and this can influence many audiences to follow their movie stars' behavior and help people and society (Rai \& Tanwar, 2015).

\section{Conclusion}

In this paper, I have presented the definition of social control according to sociologists the purpose of social control, and its forms in a community. Also, I have explained the implications of using social work or social policy as a tool of social control on individuals and social policy. Also, I said that since social workers are used as a tool of social control by the state government to serve its policy, they should use this opportunity to apply the profession of social work to serve people in need and use the community resources to serve individuals, groups, the community. Additionally, social workers should play the mediator role to connect these units, together as social units complementing each other based on the social work profession.

\section{Conflicts of Interest}

The author declares no conflicts of interest regarding the publication of this paper.

\section{References}

Andrews, R. (2011). Exploring the Impact of Community and Organizational Social Capital on Government. Political Research Quarterly, 64, 938-949. http://www.jstor.org/stable/23056358

Austin, M. J. (2014). Social Justice and Social Work: Rediscovering a Core Value of the Profession. Singapore, Washington DC: SAGE Publications. http://dx.doi.org/10.4135/9781483387987

Bao, W., Haas, A., Chen, X., \& Pi, Y. (2014). Repeated Strains, Social Control, Social Learning, and Delinquency. Testing an Integrated Model of General Strain Theory in China. Youth and Society, 46, 404-424. https://doi.org/10.1177/0044118X11436189 
Bhushan, V., \& Sachdeva, D. R. (2012). Fundamentals of Sociology. Pearson Education India.

https://books.google.com/books?id=qgZFB3UOuNkC\&pg=PA157\&lpg=PA157\&dq=Soci

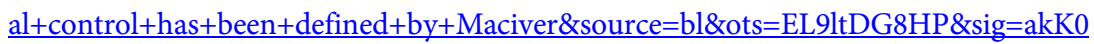

Blair, K. (2007) Social Work and the Cultural Dialogue. Critical Social Work, 8. https://doi.org/10.22329/csw.v8i1.5742 https://ojs.uwindsor.ca/index.php/csw/article/download/5742/4685?inline=1

Burman. S. (2010). Revisiting the Agent of Social Control Role: Implications for Substance Abuse Treatment. Journal of Social Work Practice, 18, 197-209. https://doi.org/10.1080/0265053042000231016

Chamlin, M. B., Burek, M. W., \& Cochran, J. K. (2007). Welfare Policy as Social Control: A Specific Test of the Piven and Cloward Thesis. Criminal Justice Policy Review, 18, 132-152. https://doi.org/10.1177/0887403406294950 http://journals.sagepub.com/doi/abs/10.1177/0887403406294950

Chaurand, N., \& Brauer, M. (2008). What Determines Social Control? People's Reactions to Counternormative Behaviors in Urban Environments. Journal of Applied Social Psychology, 38, 1689-1715.

https://content.ebscohost.com/ContentServer.asp? $\mathrm{T}=\mathrm{P} \& \mathrm{P}=\mathrm{AN} \& \mathrm{~K}=32642851 \& \mathrm{~S}=\mathrm{R} \& \mathrm{D}$ $=$ sih\&EbscoContent $=\mathrm{dGJyMMTo50Sep7M4yNfsOLCmsEmep7ZSr6y4S66WxWXS \& C}$ ontentCustomer=dGJyMPGuskq0qbRRuePfgeyx43zx

Cowger \& Atherton. (1974). Social Control: A Rationale for Social Welfare. Social Work, 19, 456-462. http://www.jstor.org/stable/23712766

DiMaggio, P., Hargittai, E. W., Neuman, R., \& Robinson, J. P. (2001). Social Implications of the Internet. Annual Review of Sociology, 27, 307-336. https://doi.org/10.1146/annurev.soc.27.1.307 http://www.jstor.org/stable/2678624

Drakulich, K. M., \& Crutchfield, R. D. (2014). The Role of Perceptions of the Police in Informal Social Control Implications for the Racial Stratification of Crime and Control. Social Problems, 60, 383-407. http://www.jstor.org/stable/10.1525/sp.2013.60.3.383 https://doi.org/10.1525/sp.2013.60.3.383

Ehrenreich, J. H. (1985). The Altruistic Imagination. A History of Social Work and Social Policy in the United States. Ithaca and London: Cornell University Press.

Evens, P. (1973). Social Control and Values in Social Work. Probation Journal, 19, 9-12. https://doi.org/10.1177/026455057301900103 http://journals.sagepub.com/doi/pdf/10.1177/026455057301900103

Ferguson, L., \& Lavalette, M. (2007). "Dreaming a Great Dream": Prospects for a New, Radical Social Work. Canadian Social Work Review, 24, 55-68. http://www.jstor.org/stable/41669860

Gambrill, E. D. (1997). Social Work Practice: A Critical Thinker's Guide. New York, NY: Oxford University Press.

Healy, K. (2000). Social Work Practices: Contemporary Perspectives on Change (pp. 74-75). London, Thousand Oaks, New Deli: SAGE Publications. https://books.google.com/books?id=TM rXunzYCgC\&pg=PA74\&lpg=PA74\&dq=Soci

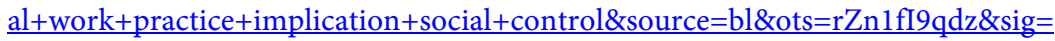

Henderson, P., \& Vercseg, I. (2010). Community Development and Civil Society: Making Connections in the European Context (pp. 97-106). Bristol: Policy Press at the University of Bristol. http://www.jstor.org/stable/j.ctt9qgnqf.11

https://doi.org/10.2307/j.ctt9qgnqf

International Council on Human Rights Policy (2010). Modes and Patterns of Social Control. Implications for Human Rights Policy. Geneva: International Council on $\mathrm{Hu}-$ 
man Rights Policy.

https://pdfs.semanticscholar.org/2bc4/e7e1019f9eb850d310c7413f881415b91632.pdf

Ivory Research (2017). Social Policy and Social Work; What Is the Meaning of These Terms and How Can They Be Used in Order to Promote Both Social Change and Social Control?

http://www.ivoryresearch.com/samples/social-work-essay-example-social-policy-and-s ocial-work-what-is-the-meaning-of-these-terms-and-how-can-they-be-used-in-order-t o-promote-both-social-change-and-social-control/

Kareev, N.N. (2013). Перед возникновением социологии в России [Before the Emergence of Sociology in Russia]. Directmedia. https://books.google.com/books?id=Tox4BAAAQBAJ\&source=gbs navlinks $s$

Kraus, M., Piff, P., \& Keltner, D. (2011). Social Class as Culture: The Convergence of Resources and Rank in the Social Realm. Current Directions in Psychological Science, 20, 246-250. http://www.jstor.org/stable/23045780 https://doi.org/10.1177/0963721411414654

Liska, A. E. (1992). Introduction to Study of Social Control. Social Threat and Social Control. New York Press.

Lyes, C. (2012). The Latent Functions of Social Work: Social Care or Social Control? https://www.academia.edu/5297524/The latent functions of social work Social care or social control

Manning, J. (2012). Suicide as Social Control. Sociological Forum, 27, 207-227. http://www.jstor.org/stable/41330920

Rai, S., \& Tanwar, C. (2015). Political Economy of Media Advocacy and Human Rights in India. Amity Journal of Media \& Communication Studies, 4, 137-148.

https://content.ebscohost.com/ContentServer.asp? $\mathrm{T}=\mathrm{P} \& \mathrm{P}=\mathrm{AN} \& \mathrm{~K}=121905815 \& \mathrm{~S}=\mathrm{R} \&$ $\underline{\mathrm{D}=\mathrm{ufh} \& E b s c o C o n t e n t=d G J y M M T o 50 S e p 7 M 4 y N f s O L C m s E m e p 7 d S r q y 4 S 7 a W x W X S \&}$ ContentCustomer=dGJyMPGuskq0qbRRuePfgeyx43zx

Reisch. M. \& Rohde, L. (2000). The Future of Social Work in the United States: Implications for Field Education. Journal of Social Work Education, 36, 201-214. http://www.jstor.org/stable/23043814 https://doi.org/10.1080/10437797.2000.10779002

Rwomire, A. (2011). The Role of Social Work in National Development. Gaborone: Department of Social Work, University of Botswana. https://ejournals.bib.uni-wuppertal.de/index.php/sws/article/view/10/32

Schissel, B. (1992). The Influence of Economic Factors and Social Control Policy on Crime Rate Changes in Canada, 1962-1988. The Canadian Journal of Sociology, 17, 405-428. https://doi.org/10.2307/3341217 http://www.jstor.org/stable/3341217

Shipunova, T. (2016). Features of the Social Control of Deviance: General and Specific Comments (Based on the Online Movement: Pickup). Journal Sociological Research, 55, 31-44. https://doi.org/10.1080/10610154.2016.1184067

Siporin, M. (1961). Private Practice of Social Work: Functional Roles and Social Control. Social Work, 6, 52-60. http://www.jstor.org/stable/23708059

Taylor, S. E., Welch, W. T., Kim. H. S., \& Sherman, K. (2007). Cultural Differences in the Impact of Social Support on Psychological and Biological Stress Responses. Psychological Science, 18, 831-837. http://www.jstor.org/stable/40064822 https://doi.org/10.1111/j.1467-9280.2007.01987.x

Villarreau, A. (2002). Political Competition and Violence in Mexico: Hierarchical Social Control in Local Patronage Structures. American Sociological Review, 67, 477-480.

https://doi.org/10.2307/3088942 
https://0-www-jstor-org.libcat.widener.edu/stable/pdf/3088942.pdf?refreqid=excelsior \%3A49cc52bfe2f2627ac6e1d52836cb0438

Weiss, I. Gal, J., \& Cnaan, R, A. (2005). Does Social Work Education Have an Impact on Social Policy Preferences? A Three-Cohort Study. Journal of Social Work Education, 41, 29-47. http://www.jstor.org/stable/23044031 https://doi.org/10.5175/JSWE.2005.200202148

Zahl, M. (2003). The Impact of Social Policies on the Formation of Social Work. Journal of Social Work Theory \& Practice. 